\title{
ARTIGAS, INeSQUeCÍVeL
}

\author{
EDUARDO DE JESUS RODRIGUES
}

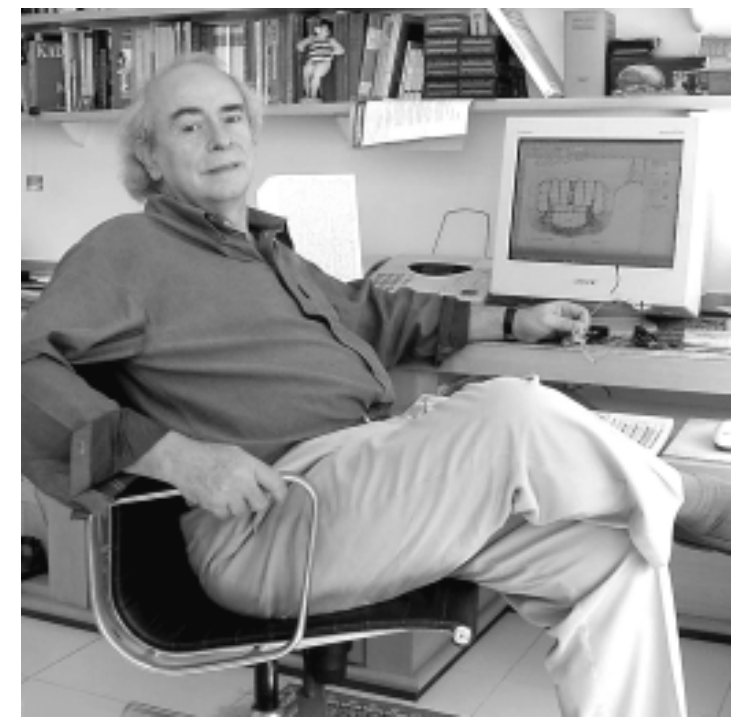

Mais que privilégio, foi fortuna o convite para trabalhar no escritório de Artigas, quando me formei na FAU. O velho, como o chamávamos - e velho, naquele tempo, não era um termo politicamente incorreto, ao contrário, demonstrava reverência a quem acumulou experiência e sabedoria - era para nós, estudantes, o monstro sagrado, encarnação da arquitetura paulista. Em meu primeiro contato com Artigas, ainda não tinha absorvido esse ideário coletivo sobre sua pessoa. A rigor, não só ignorava quem era, como nunca tinha ouvido falar dele. Recém-ingresso na universidade, no dia da aula inaugural, sentei na primeira fila da Sala dos Espelhos, abarrotada por todos os alunos da faculdade. Artigas ministrou a aula magna do ano letivo de 1968, discorrendo sobre o desenho, aula cujo teor depois se transformou em publicação e, como todos sabem, um paradigma para várias gerações de estudantes. Artigas não tinha apenas a habilidade da oratória, o carisma e a simpatia pessoal a seu favor. Tinha a convicção inoxidável dos iluminados que postulam a verdade. Aquela aula foi revelação, desvendamento de um universo inusitado para aquela turma de calouros, neófita e ávida de conhecimento. O universo que Artigas nos descortinou, desde esse dia memorável até o momento em que fomos alijados de seu convívio na academia pela ditadura militar, extrapolou a abrangência da arquitetura. Por sua mão, fomos estimulados ao exercício do pensamento e à reflexão, ao amor à liberdade, aos ideais e, sobretudo, à consciência de nossa condição humana.

Fui para o escritório de Artigas, contratado para ajudar no projeto de reurbanização do Vale 
do Anhangabaú, que, afinal, demorou um tempo para entrar. $O$ escritório, no quinto andar do prédio do $I A B$, tinha uma sala de espera acanhada. A saleta abrigava a mesa da secretária, dois arquivos de aço e um pequeno sofá, além dos armários altos que dividiam o espaço para a sala de desenho. Na saleta de espera a cena era roubada por um pilar em concreto, singular e solto no meio do ambiente, desprovido de seu revestimento e pintado em forte lilás. Ganchos de rede presos à parede indicavam que o ócio não era, necessariamente, a antítese de negócio. Da saleta, pela direita ia-se à sala do velho; pela esquerda, à copa com sua pequena geladeira generosamente abastecida de toda sorte de águas e refrigerantes. Daí se passava à ampla sala de desenho. Olhei meus futuros colegas encarapitados em antigas banquetas de aço, desenhando em pranchetas enormes, nas quais se podia trabalhar em pé, quase 2,00 metros por 1,30 , todas equipadas com espaçosos tecnígrafos. Elas davam um tom ancestral ao ambiente, com suas estruturas tubulares em cobre. Em comparação aos escritórios de arquitetura que conhecia, todos supermodernos, em que as pranchetas eram mesas baixas equipadas com réguas paralelas, aquilo me pareceu medieval. Brinquei com Artigas, a propósito de tecnígrafos serem coisa de engenheiro. Ele sorriu e retrucou: - Vamos ver se, daqui a algum tempo, você passa sem ele. Para a minha geração, a criação em arquitetura estava ligada ao lápis grosso, ao croqui generoso; onde o desenho técnico era uma tarefa maçante, meramente burocrática. Artigas nos ensinaria que a ligação entre o lápis grosso e a caneta graphos era direta, que era impossível conceber um projeto sem o controle rigoroso da construção, da concepção da estrutura até no mais óbvio dos pormenores. E a primeira de muitas lições foi constatar que aquelas pranchetas com tecnígrafo, proporcionando agilidade e precisão ao trabalho, eram extremamente confortáveis para o desenho, muito mais que as modernas mesas baixas. E ainda, que daquele ambiente ancestral nasciam as idéias mais modernas concebidas pela arquitetura paulista.

Minha primeira tarefa no escritório foi desenhar a casa Domschke. O primeiro trabalho e a primeira grande surpresa. Artigas me levou à sua sala, e sentados à mesa de pau-brasil, passou-me o serviço. Desenhou as plantas, os cortes e as fachadas, à mão livre, em pedaços de papel manteiga, mais ou menos de tamanho A4, enquanto me explicava o projeto. Falava ao mesmo tempo da solução funcional, estrutural e formal a qual adotara, evidenciando as qualidades do espaço que, como em todos os seus projetos, refletia, ao mesmo tempo, o rigor ético e a generosidade com que interpretava o mundo. Desenhos feitos e a exposição completa e clara, entregou-me os desenhos para que eu começasse a representação técnica para o anteprojeto. Argumentei então: - Artigas, nos desenhos não tem nenhuma medida, como vou saber o tamanho dos espaços? Artigas me olhou como se eu estivesse dizendo uma grande asneira. Tomou o escalímetro que estava sobre a mesa e disse-me, colocando-o sobre o desenho que acabara de fazer: este quarto, está vendo?, tem $4 \times$ $4 \mathrm{~m}$. Esta sala,... e por aí foi. Fiquei boquiaberto, 
porque ele não utilizou o instrumento enquanto desenhava o projeto para mim, e desenhou tudo em exatos um para cem. Gostaria de saber se esses desenhos ainda existem. Ficariam bem, no Museu da Arquitetura que ainda haveremos de concretizar, a partir da FAU.

O convívio entre os funcionários do escritório era harmonioso. Não havia a mesquinha disputa pessoal, tão característica desse tipo de ambiente de trabalho. Todos colaboravam com todos, e a relação era fraterna. Percebi logo que havia aí a influência de Artigas. Ele nunca precisou explicitar literalmente sua posição. Era sua atitude. Conhecia muito bem cada um de nós. Era um homem perspicaz, conhecedor da natureza humana. Lembro de uma ocasião em que eu estava desenhando em minha mesa, acabrunhado por circunstâncias particulares, que não vêm ao caso. Artigas parou ao lado de minha mesa, observando o trabalho, como sempre fazia. Em um dado momento, colocou a mão sobre meu ombro e disse apenas: - Não se deixe envolver emocionalmente. Disse a frase de generosa solidariedade em inglês, sutileza sua, para ser menos invasivo. Nunca comentei com ele minhas infelicitações, mas como não Ihe escapava nenhum detalhe, sabia exatamente o que ia por minha alma. Conhecia a cada um de nós e nossos familiares e amigos, não só pelo convívio no ambiente de trabalho, como também de sua casa, a qual freqüentávamos a seu convite, nas festas, jantares e reuniões. Por sua vez, freqüentava nossas casas, sempre que convidado. Essa atitude fazia parte de sua maneira de ser, seu desejo de conhecer-nos melhor, e, principalmente, demonstrar que nos respeitava. Assim, conferia, a cada um de nós, a dignidade e o respeito pessoal que em outras relações semelhantes seriam naturalmente negadas pela arrogância e pela soberba. Artigas, muitas vezes acusado injustamente de arrogante, tinha a exata noção de quem era, a segurança do que sabia e a dimensão de sua capacidade de criação. Não precisava ser e nunca foi arrogante. Sua vaidade profissional, tantas vezes mal interpretada, não era certamente uma presunção.

Era freqüente, na hora do almoço, tomarmos todos juntos nossas refeições sobre a mesa de pau-brasil, forrada de papel branco. Enquanto esperávamos pelos pratos feitos encomendados, Artigas desenhava com hidrográficas coloridas no papel de forro da mesa, em escala um para um, as iguarias as quais, certamente, não comeríamos naquela refeição. A exposição gráfica de ricas saladas e lagostas era uma forma de convidar-nos ao exercício da imaginação e da invenção. Naquelas ocasiões não havia conversa banal. Mesmo os temas mais comezinhos, pela riqueza de pontos de vista inusitados que Artigas a eles introduzia, transformavam-se em motivo para alguma reflexão. Não raro cobrava nossa opinião nos projetos em que trabalhávamos e estimulava nossa contribuição.

Certa ocasião surgiu uma questão prática de trabalho, e Artigas resolveu comentar pelo viés de uma parábola. Contou então um caso, narrando um acontecido em uma de suas viagens ao Leste Europeu. Dera de presente à secretária de alguma instituição, da qual já não lembro, um par de meias de náilon, artigo de luxo pela raridade, naquelas paragens, na época do sucedido. Descreveu com realismo a reação da moça, a qual passou rapidamente de uma alegria exuberante ao pranto. Quando indagou o porquê das lágrimas, descobriu que não era uma conseqüência emocional pelo ganho, mas uma dor antecipada pela perda: ela não poderia usar suas meias no trabalho, porque a cadeira que usava, de madeira, tinha umas farpas na perna as quais, fatalmente, desfiariam a trama da meia. Artigas pediu que ela se levantasse, colocou a cadeira sobre a mesa e, com seu canivete, desbastou as farpas. Com esse exemplo, deu-nos uma lição do pragmatismo necessário, rebatimento para o assunto do qual falávamos, sem outro comentário. Em outra ocasião, lembro de estar desenhando a passarela do aeroporto, para a qual resolvi dar uma contribuição pragmática. A passarela, em uma de suas extremidades, tem uma escada, porque não havia condição técnica para uma rampa. Artigas pensou a composição formal das escadas com umas empenas em concreto, as quais, além de resolverem a questão estrutural e dar graça à forma, tinham ainda a função de proteger o espaço do ruído da avenida que a passarela transpunha. Essas circunstâncias tornavam, a meu ver, a escadaria recôndita o suficiente para que, durante a noite, as pessoas a usassem como sanitário. Não tive nenhuma dúvida em locar, no patamar intermediário, um hidrante na empena. Quando o velho viu o desenho, perguntou-me: - 0 que é isto? Respondi que era um hidrante, do 
que ele riu profusamente. - Você acha que a passarela vai pegar fogo?, perguntou. Respondi que não, o hidrante seria um meio facilitador para a higienização da passarela, em função do fatal uso como sanitário público. Artigas me perguntou, então, onde eu acreditava estar o erro: em não haver uma torneira na passarela, ou em não haver sanitários públicos? Dei a reposta óbvia, e ele retrucou: - Então? Você quer justificar um erro com outro? Entendi, assim, que colocar um ponto de água na passarela para a finalidade pretendida significava aceitar o uso da passarela como sanitário. Seria institucionalizar uma prática errada, dando-a como correta. Apaguei rapidamente o estúpido hidrante, mas ficou para sempre a lição que a ação pragmática é inconseqüente, se não tiver base teórica sólida.

Um exemplo de aplicação prática conseqüente, de invenção como resultado da necessidade, fornecia-nos Artigas, quando falava dos expedientes a que recorria, no tempo em que era construtor. Naquela época, de escassez de matérias-primas e de tecnologias avançadas, era hábito dos construtores de sobrados deixarem o vazio da escada para depois, chamarem um profissional especializado, o escadista, para executá-la em madeira. Artigas, revolucionário em sua arte, não se conformava com essa circunstância, não por considerar incompetentes os escadistas, ao contrário, mas pela perda do controle formal do espaço. Desenhava suas escadas em concreto, ousadas e inéditas. Os desenhos, no entanto, eram barreiras intransponíveis na comunicação com os mestresde-obra. Passou, então, a fazê-los no chão, diretamente sobre a projeção do que seria a futura escada. O mestre montava as formas para os patamares e piso de degraus diretamente sobre o desenho, fundindo depois as lajotas. Nas paredes desenhava o desenvolvimento da escada, na qual as peças fundidas seriam engastadas. Dessa forma, o mestre realizava o ideário do espaço, que não conseguia absorver do desenho. 0 velho era tão solícito e abundante nas descrições que nos fazia, e delas não escapavam nem mesmo os pequenos truques construtivos, as manhas para que o resultado correspondesse ao absoluto rigor dimensional por ele exigido, para a elegância formal e o adequado conforto no uso do equipamento. Da mesma forma que falava das escadas, falava da estrutura em madeira do telhado da "casinha" (a primeira casa do terreno do Campo Belo, onde habitou por muitos anos), mostrando os desenhos e os pormenores que inventara, para eliminar espessuras visuais comprometedoras na harmonia do conjunto. Mostrava a simplicidade do recurso usado para vencer estruturalmente o balanço inquietante de um dos cantos do telhado. Em outros momentos, mostrava-nos indignado com o quanto a norma era beócia. Lembro das revelações a propósito: 0 edifício Louveira só pode ser aprovado na prefeitura, depois que Artigas concordou em incluir no desenho de aprovação umas janelas na fachada. A norma proibia fachadas cegas para a rua! Claro que as janelas nunca foram locadas na construção. Artigas se indignava com normas arbitrárias como essas, as quais demonstravam o espírito tacanho e prepotente daqueles que as compuseram. Foram normas como essa que obrigaram Warchavchik a alegar falta de recursos financeiros para não colocar adereços ornamentais na fachada da casa modernista da rua Santa Cruz. Em outro projeto, a casa da atual avenida Sumaré, Artigas locou uma casa com generoso recuo para a via, tendo uma das águas do telhado principal voltado para ela. Uma lei do século 19 proibia as águas voltadas para a rua, para evitar que, em dias de chuva, os transeuntes recebessem sobre si o volume da água escoado pelo telhado. A lei foi criada em uma época que não estava disseminado o uso de calhas e as platibandas neoclássicas ainda não tinham virado moda na antiga São Paulo. Baseados nessa lei, em meados do século 20 , os analistas municipais negaram a aprovação do projeto de Artigas, que se recusava a colocar calhas no telhado. Foi, segundo o velho, uma batalha árdua, só terminada quando ele conseguiu a revogação da lei. Ele não se conformava com aqueles que, casuística ou voluntariosamente, abusavam do poder que detinham, para nos impingir absurdos. Considerando que, nesta cidade, perdurou por muito tempo uma lei a qual previa multa para os defuntos que ressuscitassem, o velho tinha toda a razão! Aquelas conversas eram aulas magníficas, que permeavam o trabalho cotidiano, transformando-o em uma atividade prazerosa. $\mathrm{Na}$ outra casa do terreno do Campo Belo, onde nos recebia para os jantares e as festas, explicava a forma incomum da lareira, resultado da busca estética que exigia uma dimensão 
pequena na profundidade da peça. Traçava, gestualmente, sobre os planos da lareira, o corte, a dinâmica da tiragem do ar, a maneira de recolher as cinzas, concluindo, orgulhoso, que jamais vazara para o ambiente uma mínima fumaça. Sobre a mesa das refeições, os rótulos das garrafas colados na parede atestavam a qualidade do que se bebia na casa. Artigas nunca se contentou com menos que o melhor, em todos os sentidos. Quando, por circunstâncias de saúde deixou de fumar, herdei dele um saco plástico enorme, com os charutos de seu estoque. Eram especialíssimos, cubanos, alguns jamaicanos, os melhores que já provei.

Quando fui trabalhar com Artigas, tinha em mente passar no escritório apenas o tempo necessário para aprender o que ele tinha para ensinar. Foi ledo o engano. Aprendi uma coisa nova, em cada um dos dias dos quase quatro anos que com ele trabalhei. Cada novo projeto envolvia um novo conceito, uma maneira diferente de resolver um programa. Artigas era inesgotável em sua capacidade de criar e inventar, era incansável em sua vocação de educador humanista.

Certa ocasião, em 20 de dezembro, Artigas nos consultou sobre se topávamos entrar em uma concorrência para dois estádios de futebol na Paraíba. Alertou, logo de saída, que o anteprojeto seria na escala 1:50, e deveria ser entregue em 26 de dezembro, por exigência do edital. Na prancheta, apesar de enorme, caberia apenas $1 / 4$ do desenho da planta. Três pavimentos, mais a implantação, cortes e fachadas, davam umas 20 folhas de desenho por estádio. Topamos, e na medida em que Artigas ia concebendo o projeto, desenhamos, por quatro dias e quatro noites, os dois estádios. No fim da manhã de 24 , dobramos a última cópia heliográfica. Naquele tempo se desenhava com caneta graphos, e as curvas compostas eram traçadas com o auxilio do cintel. A projeção de cada viga e de cada nervura curva das arquibancadas era riscada em tracejado! As cópias heliográficas dobradas e amontoadas cobriam todo o piso da saleta de espera, com uma altura de uns 60 centímetros. Apesar do esforço, não vencemos a concorrência. Foi a única grande virada que fizemos, no tempo em que lá trabalhei.

Poucos anos depois de deixar o escritório de Artigas para seguir minha carreira profissional independente, resolvemos, Fernando Frank Cabral e eu, fazer um documentário sobre o edifício da FAU na Cidade Universitária. O projeto envolvia depoimentos de Artigas, que depois de relutar um pouco acabou cedendo seu tempo para a empreitada. Em uma das oportunidades, com o filme rodando, perguntei a ele sobre a questão do conforto ambiental no edifício. Queria registrar no documento o caráter explosivo que Artigas assumia, quando injustamente criticado. Era um componente importante de sua personalidade. Esperava mesmo que, em sua resposta, chamasse-me de zebra sem listras, expressão sua, recorrente, quando avaliava os estúpidos. Mas Artigas era sempre surpreendente. Esperto, percebeu imediatamente meu intuito e respondeu: - Quando fiz o projeto da FAU, pensei em um templo grego. Passou, então, a estabelecer as relações do templo com o prédio da FAU, falando do intercolúnio, do peristilo, da ausência de portas, das qualidades harmônicas, do ritmo, etc. E concluiu: "- E como você sabe, os templos são feitos para os deuses, que não sentem nem calor nem frio..." Artigas era brilhante, assim.

Terminado o filme, fomos à casa do Campo Belo para exibi-lo ao velho. Armamos o circo: projetor, tela, etc. Passamos, Cabral e eu, os 30 e tantos minutos de projeção olhando para ele, acompanhando, temerosos, as expressões que pudessem ser reveladoras de sua opinião. Nada. Acompanhou impassível a projeção. Ao final da exibição, acesa a luz, estávamos ansiosos pelo julgamento, importante para nossos egos. Ele nos olhou, sorriu e disse: - Podemos ver de novo? E completou, já com a nova projeção iniciando: $-E$ eu, que pensei que ia dar tudo em águas de batata!...

Inesquecível Artigas! Ainda hoje, em alguns momentos de minha vida, a memória me traz sua voz, dando o sábio conselho: "- Não se deixe envolver emocionalmente..."

\section{Eduardo de Jesus Rodrigues}

Professor do Departamento de Projeto da FAUUSP e professor orientador no curso de pós-graduação. 